such spectra as these that we shall see, and not line spectra. Further, in the case of compounds in which the molecules which give us these new spectra enter into combination, we may possibly dissociate them and observe their spectra at a much lower temperature than we can drive the higher molecular arrangement of the solid into vapour,

Such considerations as these derive additional interest and importance from the beautiful researches of Schiaparelli, which connect comets with meteorites.

Modern science acknowledges that comets are individual members of meteor swarms-not that meteors are comets' tails, as some think; this idea is, one may say, impossible to reconcile with facts-that one difference at any rate between a comet and a meteor is that one is self-luminous, the other is not till it arrives wit? in the limits of our atmosphere. If this be acknow1.uged, then to what is this difference to be ascribed? A possible cause is certainly a difference of chemical constitutiona difference between niaterials incandescent at a high temperature and materials incandescent at a low one. It is not necessary to stop to inquire how this temperature has been arrived at, but it is important to show that the question of temperature is one of the very first poinis to be attended to by those who can kring sufficiently powerful instruments to bear upon the present comet, and that the question of its actual chemical constitution is bound up with it.

But whatever be the temperature of the head there is another point which must not be lost sight of. Sir John Herschel writes concerning Halley's comct: "The bright smoke of the jets, however, never seem to be able to get far out towards the sun, but always to be driven back and forced into the tail, as if by the action of a violent wind rolling against them-always from the sun-so as to make it clear that this tail is neither more nor less than the accumulation of this sort of luminous vapour, darted off in the first instance towards the sun, as if it were something raised up, and as it were exploded by the sun's heat, out of the kernel, and then immediately and forcibly turned back and repelled from the sun." Here we have the question raised not only whether the envelopes consist of different materials, but whether the tail is not entirely or in part seif-luminous: the present comet may show that this point is not so satisfactorily settled as it is supposed to be in favour of reflected light.

Such then are briefly some of the questions at issue. It is to be hoped that our beautiful visitor will answer some of thern for us, and that when it leaves our northern skies the work may be carried on in the southern hemisphere.

J. NORMIAN LOCKYER

\section{THE CHANNEL TUNNEL}

WE fear there are still many who fail to see that any good can come of scientific research unless it has some well-defined "utilitarian" object in view. Even in this and in other comtries that are in the van of civilisation and in which education is comparatively wide-spread, the majority of mankind can appreciate a benefit only when it takes a concrete and tangible form. That love of knowledge for its own sake, that noble inquisitiveness which has been so fruitful in results during the last two hundred years, even yet belongs to comparatively few, who are still regarded by the many with a kind of im- patient pity as mere unpractical hobby-riders. Still the people who talk in this way are proud enough of the glory which their great men have shed upon their country, and would not willingly, we believe, part with it for money were this possible; and indeed how would this country appear among the nations were she deprived of the inestimable inheritance which her great sons have bequeathed to her in every department of intellectual activity? Happily, however, the race of those who decry single-eyed scientific research is getting sensibly smaller; and we firmly believe that as education improves and as higher education spreads, carrying with it the results of this same scientific research, it will disappear.

Still, a little consideration might show those who are ever ready to cry "what's the good?" that since all socalled "practical" schemes are concerned either with man's own body or with the surrounding universe, an essential part of the basis of any scheme is a thorough knowledge of the material on which it is proposed to work. Such a knowledge it has over and over again been shown is only to be attained by abstract scientific research, by investigation conducted as if the only end in view were a thorough knowledge of the subject in hand in all its scientific aspects and relations. Many instances could be given, and indeed are every day occurring, of the highest practical results unwittingly following from such investigations; and to the sceptic we could not recommend a better example of how indispensable is thorough scientific research as a basis for the useful arts than the results of the investigation into the geology of the Channel which Mr. Prestwich (the newly elected Oxford Professor of Geology) presented to the Institution of Civil Engineers last December, and which, with the subsequent discussion and maps, has just been published in a separate form. This study of the strata which underlie the Channel, and which seems to us an almost perfect example of close and careful reasoning on physical facts, is now brought forward to enlighten the projectors of a tunnel between England and France as to the nature of the material with which they will have to work; but $\mathrm{Mr}$. Prestwich distinctly states that the various formations are considered "irrespective of their relative merits in any other than a geological point of view."

Mr. Prestwich's plan is to discuss carefully all the strata whicin underlie the Channel, from the London clay down to the Palæozoic series, exhibiting distinctly their lithological characters, dimensions, range, and probable depth, and from these data deducing his conclusions as to the suitability of each formation for being pierced by a tunnel. The investigations of himself and others on which Mr. Prestwich's paper is founded were mostly undertaken from no practical point of view, and before a Channel tunnel was thought of. Mr. Prestwich, many will be glad to think-grateful, we hope, at the same time for this very practical result of pure scientific research-concludes that from a geological point of view it is quite practicable to construct a tinnel underneath the Channel, although to do so with safety it will be necessary to go very deep down. But an excellent idea of the results of the investigation will be obtained from the following clear summary with which Mr. Prestwich's paper concludes :--

"In the London clay there exists a perfectly impermeable bed of sufficient thickness, but nowhere between the two 
countries, except probably at points where the distance presents apparently insuperable difficulties. The lower chalk or chalk marl affords a comparatively impermeable deposit, also of sufficient dimensions : but from its having a calcareous base, and from the possibility of fissures, with the absence of a protecting overlie, it has great uncertainty. In the gault there is another impermeable stratum, but of dimensions too small. The lower greensand contains no beds sufficiently continuous and impermeable. The Weald clay ranges about half-way across the channel; and if a belt of it should possibly pass round at the north end of the Varne and range to Wissant, it might prove to be worth further inquiries. In the Kimmeridge clay there is again a deposit of sufficient dimensions, but with a subordinate band which may be sufficiently permeable to present difficulties, whilst, though it comes to the surface on the French coast, its depth on the English coast must be very considerable. There is, however, just a chance that the Kimmeridge clay may in mid-channel be overlapped unconformably, and at a slight angle, by the Weald clay, and in that case they might for all purposes be considered as continuous strata. The Oxford clay presents similar difficulties, in addition to its greater depth and inaccessibility. In the secondary strata the irregular lie of the strata, and the presence of faults, are contingencies important to be considered.

"On the other hand, the great mass of the Palæozoic rocks so protected by impermeable overlying strata, is of such great dimensions, and so compact, and holds its range so independently of the more irregular range of the secondary strata, that it offers the conditions most favourable for the secure construction of a submarine tunnel ; and that such strata can be worlsed in safety and for considerable distances under great bodies of water, has been proved at Whitehaven and Mons. But, on the other hand, the depths of these old rocks below the surface is very great, and they are much more dense and harder than the overlying formations.

"There is another important problem in connection with the Palæozoic rocks which such an undertaking might help to solve. The great question of the range of the coal measures under the south of England has lately. come prominently into notice; and it was, in fact, in inquiries connected with that question that the foregoing considerations presented themselves to the author. The rich coal basin of Mons and the north of France has been traced to within thirty miles of Calais, where it thins out; but, like the coal basins of Liege, Aix, and Westphalia, which form separate sections of the same great trough, to the eastward, so there is reason to suppose that other sections of the trough set in on the westward, forming other coal basins, which possibly range to the west of England (Somersetshire), passing under the north-eastern part of Kent and the Thames. Any such work, therefore, as a submarine tunnel in these Palæozoic rocks could not fail to throw much light on the subject ; while, in case it were to hit upon the line of strike of the coal measures, and could be carried on along that line, the work might prove otherwise remunerative, and tend to solve the great problem which interests so largely both geologists and the general public.

"Such, briefly, are the conditions which bear on the construction of a submarine tunnel between France and England. The author is satisfied that, considered on geological grounds alone, it is in one case perfectly practicable, and in one or two others it is possibly so; but there are other considerations besides those of a geological nature, and whether or not they admit of so favourable a solution is questionable. In any case the author would suggest that, the one favourable solution admitted, it may be desirable, in a question involving so many and such great interests, not to accept an adverse verdict without giving all those other considerations the attention and deliberation which the importance of the subject deserves.
"Under any circumstances, the difficulties are formidable. Whether or not they are insuperable are questions which may safely be left to Civil Engineers. The many and great obstacles overcome by engineering science in late years lead the author to expect that, should the occasion arise, and the attempt be considered worth the cost, the ability to carry it out would not be wanting. Various preliminary trials are, however, indispensable, in order to clear up some of the geological questions before a balance of the comparative advantages presented by the different formations could be satisfactorily settled, and before the grounds for action could be accepted."

From this it will be seen that the possibility of a Channel Tunnel remains now only with the engineers to decide. Geology has told them all the natural conditions under which they will have to work, so far as these can be known without actually tunnelling; and since so cautious a reasoner as Mr. Prestwich thinks it possible to carry out the scheme from a geological point of view, we should think that if it could be proved that the undertaking would pay, our engineers would be eager to show that the resources of their art are quite equal to its suc. cessful accomplishment.

\section{OWENS COLLEGE "ESSAYS AND ADDRESSES"}

Essays and Addresses. By Professors and Lecturers of the Owens College, Manchester. (London: Macmillan and Co., 1874.)

THIS book is due to the natural desire of the teaching 1 staff of the Owens College to have some memorial of an event of the first importance in their own history, and to give expression to the hopes that animate the institution. The Owens College was founded by a single legacy a quarter of a century ago-for the creation of a college in which Lancashire lads might study at home the "branches of learning coinmonly taught in the English Universities." It first became known in connection with its first Principal, Scott, a writer who has left nothing which explains the high rank he held among his contemporaries and especially the influence he unquestionably exercised over every young man with whom he was brought into contact. Under him, however, the College did not flourish - the number of the day students sank at one time as low as 25 -and it was only after the appointment of the present Principal, Dr. Greenwood, that it began to take root in Manchester. It has now about $35^{\circ}$ day students-not including the medical students, who have been added only this session-and nearly 800 evening students. Curiously enough, what happened in Glasgow to the disappointment of many of the wellwishers of the University, happened also in Manchester. When the new buildings, with all their increased convenience for study, were opened, it seemed natural to anticipate a great increase of students. Nothing of the kind took place. Students seem to come and go to college because they want to be taught, not because they are to have beautiful buildings to be taught in. The effect will certainly be considerable, alike on teachers and on taught, of the more commodious buildings recently erected in Glasgow and in Manchester, and it will be felt more and more as time goes on. The fact that it is not felt at first shows, however, that the wants that are satisfied by univer- 